Article

\title{
Determining Factors of Innovative Performance: Case Studies in Extremaduran Agri-Food Companies
}

\author{
Beatriz Corchuelo Martínez-Azúa *D, Pedro Eugenio López-Salazar and Celia Sama-Berrocal(D)
}

Department of Economics, Faculty of Economics and Business, University of Extremadura, Avda. De Elvas, s/n., 06006 Badajoz, Spain; pelopez@unex.es (P.E.L.-S.); celiasamaberrocal@unex.es (C.S.-B.)

* Correspondence: bcorchue@unex.es; Tel.: +34-606976912

Received: 12 October 2020; Accepted: 28 October 2020; Published: 1 November 2020

check for updates

\begin{abstract}
The agri-food industry plays an important role in the manufacturing industry in the Autonomous Community of Extremadura (Spain). The main objective of this study is to identify which business factors influence the success of the innovative performance in this regional industry. We proposed a novel theoretical model in which we analyzed the effect of six business variables. Using a multiple-case study, five in-depth interviews were carried out to measure the level of importance that managers gave to each of the variables. The study validated the proposed model in which all the contrasted variables (Management, Strategy, Structure, Culture, Climate, and Market Orientation) had a great weight for the achievement of the innovative performance. The study contributes to the promotion of the capacities and competences of the agri-food companies' managers for the development of innovative activities favoring the knowledge, the external visibility, and the competitiveness of the companies. It is also useful for Public Administrations when developing policies to promote and encourage innovation in a sector of vital importance in the rural and regional development of this Spanish region.
\end{abstract}

Keywords: agri-food industry; innovation; innovative performance; case study; Extremadura

\section{Introduction}

The agri-food industry groups a set of very heterogeneous activities, ranging from the first transformation of animal and vegetable raw materials to the production of sophisticated products such as functional foods. The importance of the agri-food sector goes beyond the quantitative indicators of economic activity and job creation. A whole series of variables interact in the sector and have a direct influence on society's well-being as a whole, in addition to the agents directly related to food production. The first function of the sector is to respond to the needs of obtaining enough food to meet the demands of citizens. Furthermore, food is increasingly required to have certain characteristics that contribute to improving the health and well-being of those who consume it. The agri-food activity is distributed throughout the territory, and especially in rural areas, which helps to avoid depopulation and to achieve an adequate territorial balance. It also has a direct impact on the environment, playing a very important role in the sustainable management of natural resources and in the adaptation and mitigation of the effects of climate change.

In the European Union, the food industry is the most important activity of the manufacturing industry, with a value of more than 1,109 billion euros in turnover, representing $13.8 \%$ of overall consumption in the EU. This sector comprises 294,000 companies that employ 4.57 million people. Small- and medium-sized companies (SMEs) represent $48.1 \%$ of the total turnover of the food sector and $61.3 \%$ of the total number of jobs it generates. A total of $95.3 \%$ of the companies in the sector are SMEs with fewer than 50 employees, and 79.6\% have fewer than 10 workers. Overall, 9 out of 10 companies are SMEs or micro-SMEs [1]. 
In Spain, the food and beverage industry is the first industrial sector in the country and is an important driver of growth that contributes to the wealth and development of the Spanish economy. According to the Industrial Survey of Companies of the National Statistics Institute (INE), the Spanish agri-food industry ranks fifth in terms of turnover with 9.5\%, after France (16.4\%), Germany $(15.4 \%)$, Italy $(12 \%)$, and the United Kingdom (11.9\%). The food and beverage industry is the first branch of the industrial sector, with 113,593.07 million euros of production value, representing $24.8 \%$ of the industrial sector, $18 \%$ of employed people, and $15.5 \%$ of the value added. The number of companies amounts to 31,342 , which represents $15.1 \%$ of the manufacturing industry. A total of $96.5 \%$ of companies have fewer than 50 employees, and 79.8\% have fewer than 10 employees [2].

Extremadura, a region bordering Portugal, is extensive in surface ( $8.22 \%$ of the country), but sparsely populated (it represents $2.3 \%$ of the total Spanish population). Its 1,072,863 inhabitants are distributed with an average density of 25.7 inhabitants per $\mathrm{km}^{2}$, compared to 92.3 in the rest of the country. The agricultural and food industry is one of the main economic activities in Extremadura and plays a key role in the regional economy. The weight of the agricultural sector and its associated industries is substantially higher than the national average. However, despite their importance and role in the regional development, the Extremaduran agribusinesses suffer from chronic problems caused by a small size, local character, lack of business clusters, and little innovative activity [3].

The agri-food industry is undergoing substantial changes and needs to include innovation within its strategies, in addition to changing its products. On the one hand, the companies must adapt their products to the new consumers and the market's food demands, in order to be more competitive and differentiate themselves from other producers. On the other hand, they must adapt their organizational structure, and especially their marketing strategies, to gain competitiveness and adapt to the international markets, which implies changes in non-technological innovation. As in other industries, innovation (technological and non-technological) gives agri-food companies the possibility of generating higher incomes and increasing their productivity and competitiveness.

Based on this framework, the main objective of this study is to identify which business factors influence the success of the innovative performance in this industry. This raises the following questions: Does the type of management influence the companies' innovative performance? Does innovative strategy influence the companies' innovative performance? Does the organization influence the companies' innovative performance? Does culture influence the companies' innovative performance? Does the organizational climate influence the companies' innovative performance? Does market orientation influence the companies' innovative performance? To anwer these questions, a multiple-case study methodology is used to analyze, from an organizational point of view, which elements contribute to the ability of companies to develop an innovative strategy. The study validates the premises of the proposed model, in which Management, Strategy, Structure, Organization, Culture, Climate and Market Orientation are factors that determine Innovative Performance.

Regarding the factors that promote and drive the innovation development in companies, the study of Jiménez and Sanz [4] classified the internal factors that are determinants of innovation. They highlighted the strategy, the organizational structure, the direction and leadership, human resources, and other factors such as technological capital and market orientation. According to several studies, the characteristics of the region are fundamental when it comes to promoting innovative activity [5-7].

Studies on innovation related to regions and regional innovation systems in Spain are diverse, although not numerous [8-10]. Buesa [8] analyzed the regional allocation of R\&D activities and their results, revealing that the existence of innovative companies is the most influential factor in the relative position of the Spanish regions and their interregional differences. Buesa et al. [9] established a typology of regional innovation systems, and Badiola and Coto [10] explained the decisive factors generating innovation in Spanish regions.

Regarding the innovative activity of specific regions and their companies, various studies have analyzed regional innovation in Spain [11]. For example, [12] examined the capacity of innovation of SMEs in Andalusia; López-Rodríguez et al. [13] focused on the study of the impact of the regional 
innovation system in the Basque Country; and in $[14,15]$, the innovative activity of companies in Extremadura was analyzed. Some international studies also analyzed regional innovation systems, such as Cooke [16] for various countries; Santos and Simoes [17] in Portugal; Niembro [18] in Argentina. Zukauskaite [19] also explained the variety of regional innovation systems and their institutional characteristics.

However, there are fewer studies focusing on the relation between the agri-food industry and innovation. Specifically, there is little research on innovation drivers, types of innovation, and innovation orientation, e.g., [20-22]. In the study of Avermaete et al. [23] the lack of empirically proven studies on innovation in SME food companies was highlighted, and Traill and Meulenberg [24] indicated the lack of research on innovation orientation and its link with organizational performance. Capitanio et al. [25] found that the driving factors of innovation in the Italian food sector could be identified as internal (endogenous) dynamics, which is important for the strategic behavior of companies. External dynamics were also found to be important, through responses to competition and reaction to high-tech products. Baregheh et al. [26] studied an innovation profile in the SME food sector in the United Kingdom. They explored the degree (radical or incremental), types of innovation (product, process, commercialization, and organization), and the innovative orientation (propensity to innovate). The study by Maarten et al. [27] presented four in-depth case studies in the agri-food sector of different countries (The Netherlands, Germany, and France). Special attention was paid to how innovation agents have successfully organized SME innovation networks. Other recent studies on the agri-food industry are those of [28-30]. The study of [29] developed and validated a measurement instrument of innovation drivers that can be used by agri-food companies to adopt strategies for improving competitiveness and innovation.

In Spain, in relation to the agri-food industry are the studies by [31-37]. Among the most recent studies, Arias et al. [37] carried out a characterization of the companies in this industry according to the obstacles to innovation. Some examples of recent studies on innovation in the Extremadura region are those of $[3,38,39]$.

The study is novel in several aspects. First, it aims to contribute to the existing literature by analyzing innovation in the agri-food industry, especially in a regional setting. Second, another novelty in relation to the latest reviewed studies was to apply a qualitative methodology (multiple case study). Third, the study addresses a theoretical research gap through the proposed conceptual model since, to our knowledge, there are no studies that have analyzed more than two variables as determinants of innovative performance.

The outcomes of this study have important implications for both managers and public administrations. In this sense, the main contribution of the study is oriented, on the one hand, at the promotion of the capacities and competences of the managers of the agri-food companies for the development of innovative activities favoring the knowledge, the external visibility, and the competitiveness of the companies. On the other hand, it is useful for Public Administrations when developing policies to promote and encourage innovation in a sector of vital importance in rural and regional development.

Moreover, the benefits associated with the study are linked to its innovative nature. The first objective of this study is to be relevant to the agri-food companies by providing advice in order to define organizational models aimed at carrying out innovative activities. In addition, from an economic point of view and its implications in the development of the region, it is relevant to understand the situation of innovation in the agri-food industry in order to establish public actions and to take measures to encourage this type of activity.

This paper is organized as follows: in Section 2, firstly, the research model is proposed and the premises of the study are established; secondly, the methodology (multiple case study) and the data used are analyzed; the main results are presented and discussed in Sections 3 and 4, respectively; finally, a conclusion is presented in the last section. 


\section{Materials and Methods}

Both the economic and the organizational analysis coincide in highlighting the importance of innovation in the complex and changing world that organizations are currently faced with. "Innovate or fall behind: the competitive imperative for virtually all businesses today is that simple. Responding to that command is difficult, however, because innovation takes place when different ideas, perceptions, and ways of processing and judging information collide" [40] (p. 1). "Innovation has become the core pillar of achievement for every organization in the current business world. Fast-evolving technology, shorter product life cycles, and a higher rate of product development, possibly boost the speed of innovation, which triggers changes in the nature of economic development" [41] (p. 66). On the one hand, innovation is a way of avoiding obsolescence, responding to changing market expectations, and is a source of competitive advantage. On the other hand, innovation takes different forms, each one as part of a multidimensional, multidisciplinary, and multifactorial process, as the product of an interaction within the organization and with its environment, in a permanent and non-linear way.

In effect, innovation is a complex activity in an organization, in which multiple variables intervene both internally and externally. It is a dynamic in which the internal and external aspects interact at the beginning and the end of the process. It is also an activity that must be considered as a deeply creative process, product, and mentality. Additionally, it seeks to satisfy internal needs in order to achieve better levels of efficiency and quality that result in greater competitiveness through better satisfaction of market needs.

Complexity is the result of a blend of learning, knowledge, creativity, and management. This combination fosters the use of both the company's own resources as well as external resources, thereby seeking to leverage the process of differentiation, with the aim of gaining a competitive advantage.

Therefore, there is a set of variables that intervene to make all of this possible: (i) a Culture that drives an adequate mindset [28,42-44]; (ii) a Structure that organizes work in a way that enhances human capital [45,46]; (iii) a Strategy that sets a course and establishes the "how to do" [47-51]; (iv) Management that acts proactively, not only creating appropriate internal conditions, but also external ones, in the management of complementary resources [52-66]; (v) a Market Orientation that establishes the environment-organization relationship as a source of ideas, recommendations, adjustments, and benchmarks [67-71]; (vi) and, finally, a Climate capable of creating the enthusiasm and commitment necessary to achieve the objectives [42,72,73].

Based on these variables, the following research premises were established:

1. There is a positive relationship between Culture and Innovative Performance (P1);

2. There is a positive relationship between Structure and Innovative Performance (P2);

3. There is a positive relationship between Strategy and Innovative Performance (P3);

4. There is a positive relationship between Management and Innovative Performance (P4);

5. There is a positive relationship between Market Orientation and Innovative Performance (P5);

6. There is a positive relationship between Climate and Innovative Performance (P6).

In previous studies, only a maximum of two of these factors have been set as determinants of innovative performance. This study suggests that all these factors are important and have a joint influence on innovative performance. An innovative Culture develops the mentality that leads to organizing work in an appropriate way. The Organization involves the development of the strategy that determines how to do it. It also influences the Management that generates the right conditions not only internally but externally. Market Orientation establishes the environment-organization relationship as a source of ideas, recommendations, adjustments, and points of reference. Finally, the organizational Climate is the factor capable of generating the enthusiasm and commitment necessary to achieve the objectives. Through the methodology used, a model that has not been previously developed was explored. 
Figure 1 shows the components of the proposed model that aims to determine innovative performance.

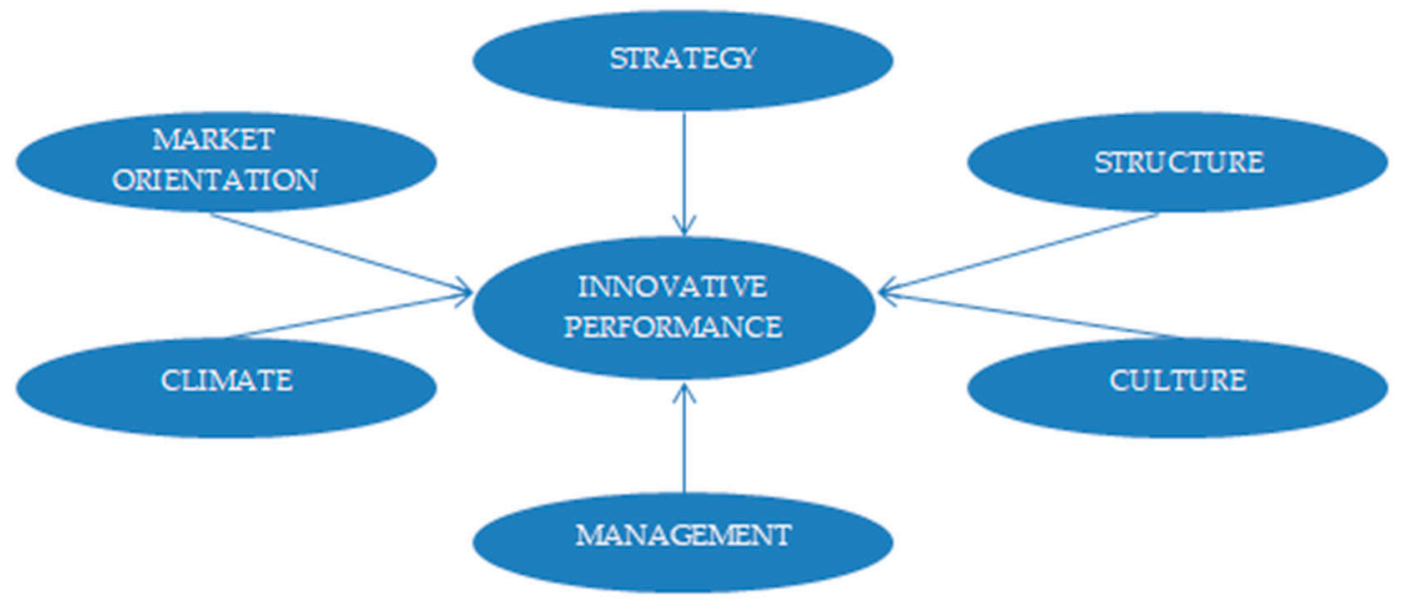

Figure 1. Conceptual model of the factors that influence innovative performance.

In order to validate the established premises, the present study used a qualitative methodology based on a multiple-case study, which enriched the understanding of the investigated aspects to the extent that the triangulation of the results enabled us to achieve a more robust analysis. In accordance with Ruiz [74] (p. 57), a qualitative research strategy "imposes a context of discovery and exploration", a circumstance that fits our objective.

According to Yin [75], this approach is appropriate because it fosters a broad understanding of the researched issue. Through case studies, the factors that influence innovative performance can be fully appreciated, and its attributes can then be widely understood through a simultaneous analysis of all its aspects. There are several categories of case studies. Reference [75] defines three categories: descriptive, exploratory, and explanatory. For this study, the exploratory approach was adopted.

Before carrying out an investigation using the case analysis methodology, the theoretical framework of the investigation must be defined, and an exhaustive compilation and review of the literature related to the topic must be done. As a previous step, we reviewed the background from other researches, hypotheses, and experimentations, which will facilitate the interpretation and analysis of the data at the end of the study.

Another fundamental element of the design in this type of methodology is the type of sampling to be carried out. In our case, the sample was selected in order to identify notable agri-food companies according to their management and performance in terms of innovation. The aim was to look for relevant examples of good practices to later extend the generalization to any type of company.

For this purpose, a report (directory) of the Extremaduran agri-food companies was carried out. The information to prepare this report came from the cross-analysis of information collected from different databases (NIS, Extremaduran Agri-food Cooperatives, and SABI) with the CNAE code 10 (Agri-food Industry), 11 (Beverages), and 12 (Tobacco). From these sources, the companies were analyzed, and according to the data available at the time, some companies were found to be duplicated, extinct, without activity at the time, or with incorrect contact information. This information was collected and completed with information from their own webpages. The report contains data from a total of 734 agri-food companies. It summarizes information on the name of the company, legal form, general contact information, number of employees, and whether they carry out innovative activities, in addition to inform if they have received public financial aid related to innovation. At the end of the report, they were categorized based on the classification of their activities. Thus, we decided which companies could join the case study, and established contact with the preselected companies, informing them of the general ideas of the research study. 
A fundamental element of the design of this methodology is the elaboration of the semi-structured interview. To do this, a script (or protocol) was prepared, including the aspects related to the selected variables previously analyzed.

The interview script consisted of the following sections:

(1) Questions about the company in general, its history, and its position in the market, evaluating the company' intensity of competition and the elements to induce this (type of product, easy access to production technology, absence of barriers to entry, the speed of technological and product change, international environment, similar products, evolution of demand, ...).

(2) The sector in which the company operates: assessment of the dynamics of change that the sector is facing (due to technological changes or continuous innovation in products and processes). Identification of the agents that promote changes in the sector (large companies, new investors, start-ups, incubators, etc.). Assessment of the importance of innovation and/or change.

(3) Characteristics of the innovative dynamics. The generation of ideas, their development, improvement, and implementation are based exclusively on intellectual capital; whether it is the product of a proactive search for ideas in their environment (research outside their internal dynamics), or the result of both (internal research and external).

(4) Innovation management. Management styles that fosters innovation in the company.

(5) Innovative strategy: it is important to structure a formal strategy, to carry out an analysis of threats and opportunities; level of formalization of strategic actions with the preparation of internal documents of the actions to be developed, accompanied by mechanisms of control and types of innovation strategies.

(6) Structure of the organization with respect to the innovative activity of the company: it is important to define who is responsible for the different activities; the existence of a high level of specialization (marketing, human resources, production, R\&D, etc.); establishment of a hierarchy of authority (organizational chart); definition of work organization (structure); ability to respond to changes in the environment.

(7) Innovative company culture: staff commitment to innovation; appreciation of the culture of innovation; values and principles to be transmitted to the people assuming an innovative role within the company; employees' attitude towards changes and innovation attuned to the strategic objectives of innovation; management's willingness to implement a proactive search for answers to internal and external problems, encouraging the development of solutions.

(8) Market orientation: evaluation of the central objective of satisfying customer needs; having fluid communication with suppliers; monitoring the actions of competitors; participation in all areas of the company in the definition and implementation of solutions given to the needs of the clients.

(9) Organizational climate: assessment of having a positive work environment that generates trust and commitment from all areas and personnel of the organization; flexibility in both the work itself and in the evaluation systems that value this work, along with creativity and innovation.

(10) Other variables that are important for achieving innovative performance that were not considered in the interview (e.g., training).

(11) In the last section of questions, companies were asked about the rating (Likert scale 1: too little 5: very much) of certain aspects that could hinder the achievement of the objectives of change and/or innovation (e.g., lack of coordination, development times that are too long, choosing the right ideas for the market, lack of financing, lack of support from public administrations). In the case of the lack of support from public administrations, companies were asked about what public actions the company would require to encourage innovative activity (public financial support, personalized advice, free training courses or seminars, etc.). 
Given the exploratory nature of the qualitative studies, neither the researchers nor the interviewees knew the totality of the information that they had to provide and collect. For this reason, the protocol was sent to the selected companies before the interviews.

Once the cases were selected, the interview was carried out and the relevant information obtained in the responses was collected. We also used other secondary information that would allow the study to be completed (date on which the interview took place, the position of the interviewed person, organization address, duration, and the method used).

Five Extremaduran agri-food companies of different sizes and branches of activity were contacted. Based on the diversity of the situation (age, size, with or without a formal R\&D department), we prepared for different eventualities in order to validate the proposed model. The contact with the companies and the interviews started in late February 2020. Table 1 shows the date, the place, the interviewee's position, and the duration of the interviews. The interviews were recorded with the permission of the interviewees.

Table 1. Sheet of interviews conducted.

\begin{tabular}{ccccc}
\hline Companies & Date & Place & Interviewed & Duration \\
\hline Company A & 28 February 2020 & Main office & CFO & $1.5 \mathrm{~h}$ \\
Company B & 9 March 2020 & Main office & CEO & $1.5 \mathrm{~h}$ \\
Company C & 13 March 2020 & Main office & CEO & $1.5 \mathrm{~h}$ \\
Company D & 8 June 2020 & Zoom & CEO & 2 h \\
Company E & 18 June 2020 & Zoom & CEO & 2 h \\
\hline
\end{tabular}

According to the objectives and the methodology established in the project, the first three interviews were carried out at the main office of the company. On 14 March the State of Alarm was decreed by the Spanish government due to the COVID-19 pandemic that affected both the companies involved in the study and the project itself. In our case, from that date, it prevented the interviews from being conducted at the company's physical location. Once the lockdown measures were eased to Phase 2 in Spain, the companies were contacted again, and in this case, the interviews were conducted through Zoom videoconferences.

Finally, to analyze and interpret the information, an initial coding framework for the interview transcripts was developed. The data obtained through the literature and the interviews allowed the coding and analysis of the cases. Finally, the functional-structural analysis was carried out after revisiting the literature again.

\section{Results}

The main results of the case study carried out are presented below.

\subsection{Case Descriptions}

- COMPANY A: Fruit and vegetables processing and preservation

Company A is a second-generation family business, founded in 1976. It currently ranks second in the world for tomato powder production. It is a primary producer whose main clients are major food processing multinationals such as Unilever and Heinz. Since 2014, the company has begun an expansion process (internationalization) through direct investment in countries with markets of great importance, such as China and USA (California).

On the other hand, its expansion at the national level led it to multiply its production infrastructures, in order to achieve not only proximity to its suppliers, but also greater stability in the supply of raw materials affected by ups and downs as a result of climatic changes. The group resulting from the expansion has an average of 600 workers, which can reach up to 1600 workers during the campaigns. It produces a total of 300 million $\mathrm{kg}$ of tomato, which is equivalent to $25 \%$ of the tomato on the Iberian Peninsula (Spain and Portugal), and 3.5\% of worldwide production. 
The innovative activity of the company A responds to the dynamics of change in the market of its clients, sustained by its R\&D department, working with the Quality department. Both of them seek endogenous and open innovation to improve the company's results.

- COMPANY B: Canned vegetables manufacturer

Company B is a limited company founded in 2015. It is located in Don Benito (Badajoz). It is a small firm of five employees. Its structure is delocalized, being fundamentally a digital company. It is mainly dedicated to the transformation and commercialization of dried tomato, smoked tomato, and tomato powder, oriented at different sales channels.

The tomato powder has competitive advantages, being able to maintain its sensory characteristics for two years. In addition, it is important to highlight its space advantages, since $1 \mathrm{~kg}$ of tomato powder is equivalent to $20 \mathrm{~kg}$ of fresh tomato. The company sells its products nationally and internationally (Italy, France, and Germany) through their website and on Amazon. In addition, in May 2020 the company began to work with the "Al Lado" supermarket chain.

Its innovative product was the result of observing a need in the market, since in Extremadura, large tomato processing industries only produce and sell in industrial quantities, and there were no companies operating on a small scale. Company B takes advantage of this market segment that has not been exploited and sells tomato powder as another condiment for daily use in the kitchen. Its vision is the introduction of a novel, sustainable, and healthy product such as tomato powder in all kitchens of the world. However, since its inception in 2015, it has encountered a number of difficulties. On the one hand, the lack of market and competition; on the other hand, the inability to get the message across to the consumer. All this means that, at present, they are focusing their efforts on investing in marketing and advertising to relaunch their products.

- COMPANY C: Olive oil manufacturer

Company $C$ is a small company founded in 2015. It belongs to the subsector of the extra virgin olive oil manufacturing and its subsequent packaging and marketing. It has a staff of five people.

The company has modern facilities, and it owns olive groves of Moorish olive variety. Its product portfolio also includes sherry vinegar, fragrant wine for cooking, aceiterol (an active ingredient in cosmetics), and olive leaf tea. They are olive oil exporters, with a presence in Japan, Mexico, USA, and Germany, among other countries.

- COMPANY D: Wine manufacturer

Company D is a family winery that was born in 2003 from the decision to realize a longstanding family desire. The company's objective is to create its own high-quality brand and, in addition, to promote the sale of bottled wine. They make a limited range of organic white and red wines. Their innovative activity responds to the development of a select and distinguished product that the firm achieves through the R\&D investment oriented at clients in a specific market niche.

The company has recently started exporting to clients in the UK, Belgium, and Portugal. They have obtained distinctions and prizes in competitions and fairs, in addition to being named "Bodeguera de Honor" in 2017.

\section{- COMPANY E: Wine manufacturer}

Company E is an Agrarian Transformation Company (ATC), founded in 1982 and located in Almendralejo (Badajoz). It is a family business, with a tradition of more than five generations in the cultivation of the vine and the production of quality wines in Extremadura. They seek excellence in their wines, and, for this, they control the entire value chain, from the field to the winery. They are pioneers in the introduction of cultivation and varietal techniques in the Tierra de Barros area, near Almendralejo (Badajoz). The wines they make are: red, white, and semi-sweet, under the Ribera del Guadiana 
Designation of Origin. In recent years, they have started to produce a sparkling wine, on which they focus all their efforts, building a second winery in 2019 for its exclusive production.

Since 2006, the company has begun an expansion process, opening a restaurant within the winery facilities, where they carry out tastings, pairings, events, and guided tours. In this way, the business materialized a new path of growth through the diversification of activities and the promotion of the wine culture. The whole of its industrial activity totals 25 workers. Of these, 10 employees work in the winery, 5 employees work in the restaurant, and the rest work in the cultivated fields.

The innovative dynamics of the company are governed by the characteristics of the wine sector: intense dynamics of change, mature, and strong competition. Accordingly, the company's responsibility has been aimed at promoting growth, business activity, and the diversification of its products, producing quality wines and disseminating the cultural feeling of the wine.

The firm sells their products nationally and internationally, with their main clients being Portugal, Germany, and France. The recent participation in the Wine Marketing Plan of the Common Market Organization (CMO) has allowed it to expand to other markets, such as the USA or Japan.

The intense dynamics of change in the wine sector and the market demands have made it necessary for the company to constantly innovate, introducing new products (the "cava"), improving its infrastructures, and investing in technology. The firm also improved its corporate image in 2017.

Table 2 shows the main characteristics of the interviewed companies. 
Table 2. Characteristics of the interviewed companies.

\begin{tabular}{|c|c|c|c|c|c|}
\hline & Company A & Company B & Company C & Company D & Company E \\
\hline Company foundation & 1976 & 2015 & 2017 & 2017 & 1982 \\
\hline Employees & 600 & 5 & 3 & 3 & 10 \\
\hline Subsector (NACE Code) & $\begin{array}{l}\text { 1039-Other processing and } \\
\text { preserving of fruit and vegetables }\end{array}$ & $\begin{array}{l}1039-\text { Other processing and } \\
\text { preserving of fruit and vegetables }\end{array}$ & $\begin{array}{l}\text { 1043-Olive oil } \\
\text { manufacturing }\end{array}$ & 1102-Wine processing & 1102-Wine processing \\
\hline Operating income $(€)$ & $109,874,990$ & 41,978 & $1,011,435$ & 22,373 & $1,467,594$ \\
\hline Profit or loss $(€)$ & $5,859,087$ & $-44,110$ & 906 & $-82,051$ & 74,147 \\
\hline Total assets $(€)$ & $131,494,306$ & 51,425 & 426,698 & 409,415 & $4,257,227$ \\
\hline
\end{tabular}




\subsection{Strategic Dynamics and Management}

- COMPANY A: Fruit and vegetables processing and preservation

Due to the characteristics of the sector and the magnitude of its production, company A moves within an environment in which competition is not very intense. It is a mature sector, in which the organizations are constantly growing, resulting in the existence of only a few large firms.

CFO: "We are the first transformation, we are not going linear, we are the first transformation and we sell to large food groups. We do not make a single product, we also produce concentrated tomato, tomato powder, tomato cubes, sauces ... a wide range of products."

However, the entry of new producers in the market generates some concern, especially because they may have different treatments for their products.

CFO: "Ukraine has entered the tomato sector in recent years; in addition, it has a series of advantages with EU community tariffs."

In summary, the characteristics of the sector lead to a higher competitive intensity at the international level than at the national level.

CFO: "We live in a global world, in the end, we are not competing with the Extremadura factories, not even with the Portuguese ... imagine, if 37 million $\mathrm{kg}$ of tomato are made worldwide and in Spain there are $3 . . . "$

Working as a team with all the area and production plant directors, the CEO creates a climate in the organization in which emotional intelligence prevails; there is permanent horizontal and vertical communication, which means that, despite the size of the group, coordination is successful.

CFO: "In our case, when acquiring several factories, each factory thinks that its way of working is the best, so when we acquire a factory, the first thing we do is to listen and see the way they are working. We are always open to learn. What we seek is to achieve synergy. We try to take the best from each of the plants. Our CEO, one of the things that he always values, is that all jobs are important in the value chain. For him, a department head is not more important than a mechanic. He often says it. People also like to listen to him. I believe this is the way it should be at work and in life, management is essential. And having people, trained, motivated people, and people with emotional intelligence."

All this dynamic is punctuated by a culture that, through the search for excellence, drives up the levels of competitiveness, dynamism, and innovation necessary to maintain the high standards required to consolidate its competitive position, both nationally and internationally.

CFO: "We focus on our clients, looking to achieve the perfection that the client wants. Our CEO has always advocated being customer oriented, differentiating ourselves from the rest of the sector, doing what the competition does not. We have to do things differently."

After the expansion, the company is at a stage of consolidation, centralization of information, and decision.

CFO: "We have had organic growth. Nowadays, we are focused on homogenizing everything, on linking all these acquisitions, each factory..."

Their market orientation also implies to maintain the links of collaboration and support to their customers and suppliers. The company responds, with their innovative dynamics, to the constant demands of their environment. They also monitor the movements of the competition, leading it to structure appropriate responses to achieve a sustainable competitive advantage. 
- COMPANY B: Canned vegetables manufacturer

Company B is a small company with a wide range of tomato products: dried tomato, tomato powder, smoked tomato, "salmorejo", and "gazpacho" powder. The novelty of its products is at the consumer level (supermarket shelves). However, the lack of information of the products' properties is considered to be the main obstacle for its commercialization, followed by the difficulty of accessing the broad-spectrum distribution channels.

CEO: "The commercial distribution is concentrated on three or four firms that, unfortunately, are too dominant, both by trend and by purchase. One of them is close to $30 \%$ of the distribution to the final consumer."

To avoid these difficulties, the company opted to digitize part of its commercialization.

CEO: "We consider ourselves a digital company and we try to do everything online. We try to sell by WhatsApp, Messenger, and we have a chat. Those have been our main innovations, although perhaps too advanced for a society that is satisfied with its sales channels."

Company B developed an innovation strategy that involved the production and marketing of tomato powder in small quantities for domestic use. The need to take advantage of this market gap was detected, where tomato powder could be used as another condiment for daily use in the kitchen, similarly to paprika or salt.

CEO: "In Extremadura, Conesa and Transa are the main producers of concentrated tomato. They sell large quantities in containers. We sell a 20 gr bottle, so we understood that there was a market."

The organization has faced a series of difficulties since starting its industrial activity, which caused changes in its innovation strategy. It is difficult for the consumers to understand and accept the use of their product as another seasoning. This made them focus their efforts on investing in marketing and advertising, allowing them to later relaunch their products.

CEO: "We have had great difficulties to make our product understood [ ... ] We noted that we were not able to send the right message to our clients. For this reason, we decided to innovate in advertising and marketing, relaunching our product."

Another mechanism adopted in its novel approach is to adopt the "pull system" (launch the process of creating value from orders).

CEO: "We try to work 'just in time'. We have machinery that allows us to work very quickly, so, from the moment the order comes in, we are responding to Amazon, and in less than $24 \mathrm{~h}$ our product is delivered."

The international presence of its products through Amazon reaches France and Germany. In the interview, the CEO first said that they had no competition, although later he changed his opinion, and said that their competition came from substitute products and that, in this sense, they face great competitors.

CEO: "We have not analyzed well our competition. We thought that our competition did not exist, because our product was not on the market, but the reality is that our competition is substitute products. For example, at dinner, if we decide to have a tomato cream, instead of sausages. Well then ... our competitor will be Oscar Mayer [... ] At the end, we realized we have made big enemies, like Nestlé, Unilever ..."

Throughout the process of redefining the company's innovative strategy, the figure of the manager adds value, even if the role that this management has in a delocalized and practically virtual company is different from other companies, using different tools and mechanisms. 
CEO: "Management in our organization adds value, but it is distributed. With responsible people, it is not so important [ ... ] There are tools to manage tasks, assign tasks, and we can use offshoring tools."

Company B has a matrix structure. Responsibilities are spread across departments and people, allowing the information to be accessible to all areas. It is also important that the employees develop a commitment culture within the organization, where a good work climate prevails.

CEO: "[ ... ] it is a project in which there is a commitment from the people who work here and that is culture." "The work environment is essential to be able to get to something specific."

Company B's market orientation is to create and understand the relationships between its customers, suppliers, and competition, responding to the innovative dynamics the market needs.

CEO: "It is important to talk to our clients or potential clients [ ... ] We visit markets to know about people's need, visit fairs, see what is being done on social networks, ..."

- $\quad$ COMPANY C: Olive oil manufacturer

As a small young company, Company $\mathrm{C}$ is oriented to a market segment where facing the great generalists is avoided by applying a focus strategy. Nationwide product distribution is done on-line, in gourmet stores, and in some supermarkets, not in large chains such as Mercadona or Carrefour.

Nevertheless, its market niche does not have a high price elasticity and the company leans towards a high-quality oil: the extra virgin olive oil. This strategy is accompanied by the internationalization of the product, which not only offers superior quality but is also an ecological product that generates $50 \%$ of the company's sales.

CEO: "The idea of oil as a healthy product does not work here: people do not understand the olive oil for its properties, they only see it as a condiment. Outside of Spain though, things are different. People value its beneficial properties beyond its organoleptic properties. Finally, we had to survive and decided to go outside where consumers value the product. We export to Taiwan, Japan, Canada, USA, and Europe, in countries like Germany. Everything we export is organic."

These markets not only expect superior quality (with its extra virgin olive oil), but also the health benefits, and the firm is developing another of its product variants through exogenous research. One of its innovations is the olive oil to be used as raw material in cosmetics. Its research process involved the universities of Madrid and Valencia, some Extremaduran private and public companies, and the University Hospital of Badajoz, through the dermatology department.

CEO: "Nowadays, we are working with the Foundation for the Training and Research of Health Professionals in Extremadura (Fundesalud), the Extremaduran Health Service (SES), the sub-directorate of pharmacies, the Association of Sociosanitary Care of Nursing Homes Residences (ASOREX), and the Extremaduran Service for the Promotion of Autonomy and Care for Dependency (SEPAD)."

Therefore, the importance of innovation is crucial for the company, although the time involved in the investigation process stands out as a major obstacle.

CEO: "Research is in the gene of this company and, fortunately, its owner is also in favor of innovating. Nowadays, if you do not innovate you are dead." [ . . ] "Every research study that we have carried out took a long time to prepare, especially the documentation. Carrying out a clinical case lasts at least four months, and any research project lasts for a year or more."

All of this has been made possible thanks to the teamwork within the company. 
CEO: "Creating a positive work climate is essential. I firmly believe that the most important thing in the company is the human team, that it makes all the difference and it is also the most difficult to manage, without a doubt. I think that currently you have to be more of a team leader and less of a boss..."

And guided by a strategy that sets the future direction of the company.

CEO: "As a manager, I am in charge of planning and I try to follow a strategy. Nevertheless, along the way, you encounter a series of difficulties and have to adjust according to those obstacles."

To finally achieve the most important thing in the company.

CEO: "Yes, of course, you are watching and analyzing what others do all day. But you do not do it with the idea of stealing ideas or that they are going to take yours, what I want is to improve. What I want to do is to add value to the customer's life, and finally, solve the problems that the consumer needs to solve."

\section{- $\quad$ COMPANY D: Wine manufacturer}

Company $\mathrm{D}$ is a family business. It is a recent winery, whose origin comes from the lifelong interest and desire of the father of the family. For a long time, like most of the farmers in the region do, the family delivered the grapes to cooperatives or private wineries. However, the father instilled in the children an interest in wine and wine-making as a business. When the father died, the family considered starting the project of setting up a winery. Initially, only two brothers worked in the winery, but when their mother retired, the interviewee also joined the company.

CEO: "We have a lot of competition. In 2003, we created our own brand. In 2007, all the vines had already been dedicated to organic farming. The project was born with the idea of selling our own quality wines. But we did not do it that way. In 2017, after ten years had passed, we decided that we had to renovate the company."

At that time, the entire bottling project began to take shape. They decided not to sell the wine in bulk anymore and started making their own wine. In 2017, Company D was born as an employee-owned company made up of three brothers and they began to manufacture and bottle their own wine. Each brother has defined his role and responsibility within the company, although there is collaboration in all aspects that do not require much specialization.

The company innovates to carve itself a place in the market despite the great competition. The innovation was brought on by the market conditions that demanded a sweeter type of wine, difficult to produce in an ecological way. So, they began researching to achieve different and totally organic wines. Currently, they have a limited range of wines (white wine from the Cayetana grape, native to Extremadura, and Tempranillo red wine, from a national grape). Two of their wines include innovations: white wine with "aloe vera" and red wine with "reishi" (a mushroom with beneficial properties). The company has a clear attitude to promote innovation in order to evolve as a company and differentiate itself from the competition. They constantly look forward to doing something new and different, and this implies continually researching and seeking new opportunities.

The company has also started an internationalization process, with clients in the UK and Belgium, along with bulk sale in Portugal. They also have multi-portfolio collaborators in different parts of Spain to sell their products.

There is no formal strategy in the company. However, actions are planned with the aim of meeting sales objectives, in addition to promotional tasks, and working on product innovation.

CEO: "The company, which is us, has not established a formal strategy. I have a long-term goal, not a short-term one. And my older brother also has a long-term goal, which is to sell all the bottled wine. 
Now the important thing is to create a brand. In the actions we are taking we do not measure what we sell, especially since it is very complicated. I must do it; I should do it. What we do is to plan the actions, and we, of course, want to reach the sales objective. In addition to the actions of sale promotion, we are going to invent things, and innovate and experiment with wines."

A lot of dynamic changes are observed in the sector, mainly in the sales channels. In this sense, the company requires a specialized professional to carry out the online marketing, which consists not only of online sales but also of a set of actions to achieve a good positioning.

CEO: "Before, the wineries were a bit traditional, with traditional sales channels, and I, who have been training on the internet for some time, could see that even the big wineries did not change either, perhaps because they thought they did not need it, or it was not their channel. But now, many things are being done. Many did not have their online store, only their very glamorous website, and now they already have their online store."

Given the current situation caused by the COVID-19 pandemic and the interruption of their activities, they have sought new means to make themselves known to their clients, such as the development of an online tasting that brought together more than one hundred people, and for which the company has achieved recognition.

CEO: "You have to move a lot and make yourself known everywhere, make a lot of noise, do a lot of crazy things. Do something strong, different. There is too much information around."

Its market orientation seeks online positioning through marketing, that the company understands as a set of many actions in which they are being trained and assisted by professionals, as a way of differentiating themselves from their competitors.

- COMPANY E: wine manufacturer.

Company E is a family business, dedicated to producing quality wines for several generations. Its strategy is not only to produce quality wines, but also to develop and promote the culture of wine, in order for the consumer to know and grasp the concept of well-being associated with the winery.

CEO: "This is a family business that gathers the tradition of viticulture. We follow an ancient culture such as the wine one, but at the same time, we try to be an innovative and modern company that wants to become a benchmark in quality wine within Extremadura."

The wine sector is a traditional sector with great dynamism, where the main changes are introduced by young wineries. It is also a sector characterized by intense competition. There are 4300 wineries and 96 Designations of Origin only in Spain, making it necessary to develop strategies that lead to market differentiation.

CEO: "Innovations are continuous, both in the bottle, the label, and the wine itself [...] It is also a very traditional sector, where the innovations are carried out by the new wineries, with semi-sweet wines, sparkling wines ..."

The organization seeks to differentiate itself in the market and professionalize the company. In recent years, some improvements to their industrial facilities have been made, allowing them to improve processes within the winery. They also included management systems, improvement of the corporate image, and new products.

CEO: "Since I work here (three years) we have made a record of agro-industrial incentives ... we have also implemented an ERP management system, which is a system that allows integrating the accounting and traceability. We have also implemented a quality standard, ISO 22000. In 2017, we launched a new corporate image ..." 
Currently, the firm focuses its efforts on opening up the market at a national and international level, despite the difficulties that the company has encountered while doing so.

CEO: “The market in Madrid is very interesting. I've been trying to find a distributor in Madrid since I started... The one who is positioned is HABLA, but of course, HABLA has an investment capacity in Marketing that we do not have for now."

CEO: "We are trying to open a market in China, it is difficult, we have not sold anything yet..."

In 2006, they decided to diversify their activities by opening a restaurant within their facilities. In this way, they materialized their growth and the diversification of their activities, promoting the culture of wine through the preparation of tastings, pairings, events, and ecological routes within their facilities. In 2019, they included a sparkling wine in their products. The sparkling wine market is growing and the profit margins are higher than those provided by still wines. To make this Brut Nature, they made a significant investment, the construction of a winery valued at $€ 1,000,000$.

CEO: "We are targeting the sparkling wine market; it is a growing market and a highly valued product abroad. We make a Brut Nature and we were trying to enter the D.O Cava, but they told us that in a winery that already had grapes from other municipalities than Almendralejo, you cannot make cava. [ . . . I In 2019, we built a new winery, valued at $€ 1,000,000$, to produce cava. The objective is to make a higher quality curve than is being made now in Extremadura."

In the strategic dynamics of the company and throughout the innovative process, the manager is the main actor, in charge of guiding the strategy of the company, promoting the culture of wine within the organization, organizing the structure of the company and its market orientation.

CEO: "Without the manager's involvement, it is impossible to innovate, I believe that innovation has to come from the bottom up and from the top down... In innovative processes, the manager's job is to facilitate and enhance culture."

Company E is structured in specific departments and functions, where the work environment is essential for the development of an innovative culture and the commitment of workers.

CEO: "The climate is fundamental, if you don't have a good climate within the company and a good environment, it is very difficult for innovation to emerge, because innovation must arise from the trust of the workers, who propose initiatives for the company. So, if there isn't a good atmosphere and the workers go about their business because they know that they will not be listened to, then maybe you are missing out on innovations [ ... ]. The innovative processes come from the staff of the winery who are working day by day with the wine or with the production processes and they themselves are capable of creating the innovative process."

The organization develops internal communication within all areas of the organization. It also maintains contact with its customers and suppliers, which helps them understand their needs and demands. He watches his competition to know what they are doing, although he claims that not as much as he would like, due to the lack of resources.

CEO: "We have two people in the commercial department who are constantly traveling and moving abroad, seeing what the market needs are, seeing what the consumers are asking for and trying to meet their expectations. [ ... ] We have had a problem with a cork stopper and the supplier himself has told us that the cork improves the quality of the wine [... I In relation to the competition, we do not monitor the competition as much as we would like, due to lack of resources." 


\subsection{Cross Analysis of the Cases and Variables of the Proposed Model}

\subsubsection{Regarding Innovative Performance}

COMPANY A, a large company, develops process and management innovation, a product of the expansion dynamics that began in 2014. In addition, it started another process in its products by expanding its lines, in response to its customers in the development of sauces.

COMPANY B, a small young company, develops and patents new products, as well as innovation in marketing through the packaging of its products and its online marketing and management system.

COMPANY C, one of the most dynamic, develops through open innovation with the academic, public, and private business sectors, a new raw material for the cosmetics sector, in addition to products such as olive leaf tea. It also innovates in marketing, catering, wine tourism, and strategic marketing mechanisms for their products.

COMPANY D, another small company, a relatively young wine producer, develops product innovations, differentiating itself with unique products in the market and by innovating in marketing through "virtual tastings" with its clients, achieving the positioning of its products both nationally and internationally.

COMPANY E, with a great position in the Extremadura wine sector, is initiating a process of innovation in its business model and product, entering the Cava sector.

\subsubsection{Regarding the Variables of the Model}

The variables proposed in the research model were validated formally, or informally in the case of the relatively smaller organizations.

This is how all the premises were positively valued as determinants of innovative performance by all the participants in the multiple case study (see Table 3).

$\mathrm{P} 1$. There is a positive relationship between management and innovative performance: validated.

Management that acts proactively in the handling of complementary resources, not only creating appropriate internal conditions, but also external ones.

P2. There is a positive relationship between strategy and innovative performance: validated.

A strategy that sets a course and establishes the "how-to".

P3. There is a positive relationship between culture and innovative performance: validated.

A culture that encourages the right mindset.

P4. There is a positive relationship between structure and innovative performance: validated.

A structure that organizes work in a way that enhances human capital.

P5. There is a positive relationship between climate and innovative performance: validated.

A climate capable of creating the enthusiasm and commitment necessary to achieve the objectives.

P6. There is a positive relationship between market orientation and innovative performance: validated.

A market orientation that establishes the environment-organization relationship as a source of ideas, recommendations, adjustments, and benchmarks.

Table 3 summarizes the most relevant aspects of the results of the case study. 
Table 3. Results of the case study.

\begin{tabular}{l} 
Management \\
\hline COMPANY A: "Management is essential and having trained, motivated people with emotional intelligence." \\
COMPANY B: "The one who leads the dynamics of innovation is management, coordinating and delegating tasks." \\
COMPANY C: "Management is the starting point of all action. I told myself I need a manager who will help me get all this up and \\
running." \\
COMPANY D: "As of 2017, I began to shape the bottling project and that is when Bodegas XX was born as an employee-owned \\
company, shaping the commercial and marketing part." \\
COMPANY E: "Without the manager's involvement it is impossible to develop any corporate innovation ... " "
\end{tabular}

\section{Strategy}

COMPANY A: "There is a document that guides the strategy of the company; The Mission is 'to be a benchmark in the tomato sector' and the vision is known, we have a SWOT and so today, because we act."

COMPANY B: "Strategic planning, defining where it is going to add more value."

COMPANY C: "As a manager I am in charge of planning and we are trying to follow a strategy. The strategy is defined as formally as I can. I define the strategy formally, but another thing is if we can implement it."

COMPANY D: "The company, which is us, has not established a formal strategy. I have a long-term goal, not short-term. And my older brother also has a long-term goal."

COMPANY E: "We do documents every year, it is a business plan, which can be considered a strategic plan."

\section{Structure}

COMPANY A: "Specialization is important as long as there is communication between the areas. The departments must be interacting; we have committees in which the heads of each area from other factories come."

COMPANY B: "The structure is a matrix [...] It gives you strength, because the information is accessible and all workers can respond, although we still do not have a registration, we have a documentation system on which we act, to be able to see who has done what."

COMPANY C: "We are three people working, one is more focused on production, another on administration and accounting, and finally I am dedicated to the management of the company and innovation. As we are less now, we have to do a bit of multitasking." COMPANY D: "Everyone has their role, but we help each other. Teamwork is very important."

COMPANY E: "In the wineries we work 10 people and in the restaurant 5, and if you count the people who work in the fields, we would be about 25 people in total."

\section{Culture}

COMPANY A: "Culture is the engine that influences the organization. Human resources have to work so that all employees follow the culture and the company values."

COMPANY B: "It is important that there is a culture."

COMPANY C: "Within our company we have innovative and investigative dynamics, that is our gene, to add value for the client and solve their problems, these are fundamental aspects that guide our behavior."

COMPANY D: "Values that prevail in the company are wanting to evolve, differentiate ourselves from the competition, do something new."

COMPANY E: "We seek excellence, to make things better every day and we try to improve and make a place for ourselves in the world of wine."

\section{Climate}

COMPANY A: "The climate is very important. A 5 on a scale of 1 to 5 , because who does not work on it is lost."

COMPANY B: "The work environment is essential that for there to be good communication and a feeling "that creates a good work environment."

COMPANY C: "A positive work climate is essential."

COMPANY D: "Teamwork is very important. Communication is essential."

COMPANY E: "The climate is fundamental, if you do not have a good working environment within the companyt, it is very difficult for innovation to emerge, it makes the workers commit."

\section{Market Orientation}

COMPANY A: "The core value that drives the company is customer orientation, we focus on our customers, seeking to achieve the perfection that the customer wants; you have to make all departments aware of that."

COMPANY B: "Market orientation is important for the company to be viable."

COMPANY C: "The customer is fundamental. We need information from our customers to know what products to put on the market. We always try to provide feedback to our clients. You are also seeing and analyzing what others are doing... what you have to do is add value for the customer, and in the end to solve the problems that the consumer has."

COMPANY D: "Even if you hire the best communicators and if you are not solving a problem for the client, if the client is not aware that they have a problem, nor are you showing it to them, then you are not going to succeed."

COMPANY E: "We have two people in the commercial department, who are constantly traveling and moving abroad, seeing what the market needs are, seeing what the consumer is asking for and trying to meet their expectations." "In relation to the competition we do not monitor the competition as much as we would like to, due to the lack of resources." 


\section{Discussion}

The purpose of this study was to analyze the influence of six variables in the innovative performance of companies. Based on a multiple-case study, five in-depth interviews were carried out to measure the level of importance that managers gave to each of the variables of the proposed model. We found that all the contrasted variables (Management; Culture; Structure; Strategy; Market Orientation; and Organizational Climate) had a great weight for the achievement of the innovative performance, all six of the proposed premises having been validated.

\subsection{Innovative Culture, Organizational Climate, Strategy and Structure}

Our findings are in line with the studies of $[42,43]$. In both of them, a multivariate model was proposed to explain the innovative performance in companies. Reference [42] outlined that the contextual factors related to the Organizational Climate and the Innovative Culture are vital for the success of the company, adding that the biggest performance is positively related to higher levels of Innovative Culture.

Culture, Organizational Climate, Strategy, and Structure are variables of vital importance for the achievement of the innovative performance. The first one (Culture), is the driver of the action oriented at innovating. It is fed by a clear definition of the vision and the mission of the company (Strategy), the way the work is organized inside the firm (Structure-flexibility), and the establishment of support mechanisms (rewarding the success and the recognition). This combination of factors is contained in the model proposed by [43], and validated through a quantitative study in the textile sector, with a sample of 287 companies, demonstrating the influence of the model's variables on innovation.

Another important issue is that the level of formalization of the strategic process was higher in the bigger companies than in the smaller ones, although these maintained a similar approach in general. The most important difference might be the way the reference documents are treated on a day-to-day basis. Nevertheless, although the processes are not formalized within the organization, they are considered key in the projection of actions to reach the proposed objectives, considering the importance of flexibility and the appropriate adaptation to the characteristics of the environment.

This finding coincides with the studies of [48,51]. The first study [51] compared this aspect to the contingent character of the strategy. The second one [48] contemplated the necessity of the structuring a cooperative dynamic and a flexible strategy. In our case, both recommendations are present in the interviewed companies.

\subsection{Management and Market Orientation (MO)}

Management is the driver, the catalyst, and the guide of the action, as well as being the center of the decision-making process. It is also the center of coordination both inside and outside the organization, assigning resources, giving guidance, and balancing the flows of resources in the ecosystem of which the organization is a part.

Management plays an important role in the identification and impulse/support of the product and process innovation complementarities [65]. Management not only responds to contingencies because of the dynamism of environmental or competitive intensity, but within its multiple responsibilities are also the management and coordination of the alliances and knowledge acquired from these [53]. Success mostly resides in the ability to manage these alliances; without a complete understanding of how they should be managed, companies could lose the opportunity offered by this kind of cooperation.

Regarding the innovation ecosystem, its complexity is due to the diversity of agents and the geographical diversity. In this sense, Mei et al. [57] found a positive correlation between the different types of linked organizations and the innovative performance, explaining that the role of the manager is important, not only regarding the solidification of the links, but also in creating the necessary absorptive capacity in open innovation. García-Morales et al. [66] refers to another important function of management, highlighting its importance through the validation of the hypothesis that a positive 
association exists between transformational leadership exercised by management and organizational innovation. This management style emphasizes emotions, values, and it stimulates creativity in employees, establishing a participative and collaborative management.

If Management is the action that orders all processes inside the organization, Market Orientation (MO) is the source that maintains the internal and external dynamics of the organization. MO facilitates the interaction with the buyer, the competition, the information administration, and the internal coordination (cross-functional coordination), focusing on solving problems and opportunities that are perceived in the environment.

The importance and positive relationship of MO with the innovative performance was perceived through the interviews of this study, coinciding with the findings of Ho et al. [70], who used a sample of 190 actors in the value chain of cattle-raising to measure the relationship between MO and innovation (the innovative performance). This study showed that there is no positive relationship between $\mathrm{MO}$ and financial performance. However, if there were a positive relationship between MO and cross-functional coordination and, in turn, a positive relationship between the cross-functional coordination with innovation (innovative performance), then there would also be a positive relationship between innovative performance and financial performance.

On the other hand, Ozkaya et al. [71], when referring to the importance of the variable MO in a firm's performance, concentrated only on two factors: The client orientation and the competitor orientation, as a source they called Market-based Innovation. This is a better criterion for small business and its dominant informality, since it ignores the coordination between functional areas, and rather emphasizes the development of competencies based on Customer Knowledge and Competitor Knowledge, resulting in an innovation adjusted to the market reality. The authors concluded that the ability to generate and use knowledge about your customers and competitors increases the performance through market-based innovations.

The results of this study show, as a main contribution to the reviewed studies, the joint importance of all of these variables on the innovative performance. The research explored and validated an issue that has not been developed previously. The six variables of the theoretical model (Innovative Culture, Organization, Strategy, Structure, Management, and MO) positively influence the innovative performance of the agri-food companies. It is important to highlight, however, that the level of formalization of the variables responds to the size of the organization. Nevertheless, neither the process informality nor the design diminishes the key role that all the variables play in the achievement of innovative performance.

\section{Conclusions}

The multiple-case study carried out has shown that there is a positive relationship between the factors proposed by the research model and innovative performance. The level of clarity and formalization of each of the factors is manifested as a function of the size and level of formalization and professionalization of the different companies.

The results conclude on the importance of Management in achieving innovative performance. Management must assume a crucial role, not only focused on the dynamics of the response to its business environment, but also on the creation of a work environment that enhances creativity. Therefore, Management has to act on multiple levels that provide feedback on the results of the action that is being carried out. Thus, the interaction with the market (MO) and the vision embodied in the Strategy (objectives and procedures) must be completed with the generation of an internal balance necessary to achieve the expected achievements (Culture, Climate, and Structure).

The research, by expanding into other aspects, discovered the criteria of the interviewees. They considered that other variables should be taken into account to enhance innovative performance, especially the variables "training" and "attitude", to contribute to greater solidity and dynamism in the generation of results. 
Finally, several aspects were also highlighted as possible obstacles to innovative performance, such as: failure to choose a correct market-oriented idea; more innovative competitors; lack of profitability in the project; too long development times; having a limited view of your client; lack of coordination; marketing and communication; a risk-averse culture; lack of support from public administrations; lack of funding or lack of staff training.

Likewise, aspects related to the dynamics of the public sector in its role of supporting the innovation of companies were pointed out, demanding the reduction of bureaucratic procedures and the increase public financial aid.

As managerial implications, this study contributes to the promotion of the capacities and competences of the agri-food companies' managers for the development of innovative activities favoring knowledge, external visibility, and competitiveness. Specifically, and based on the results obtained, the management should establish objectives and formal or informal procedures that guide the innovative action of the company. Likewise, the management should develop a climate that encourages people to innovate by providing solutions to customer needs, as well as increasing their commitment to the organization, thus allowing the achievement of their strategic objectives. Contact with customers is essential to know their needs and to be able to respond to them through innovation. Finally, to achieve an internal coordination that allows collaboration and teamwork.

This study had a significant research limitation. As a consequence of the state of alarm decreed by the government in Spain in March due to the pandemic caused by COVID 19, only three of the interviews could be conducted at the company's headquarters, as recommended by the methodology of case study. The last two interviews were by video conference because of the recommendation to avoid human movement between municipalities. This fact also limited the number of companies interviewed. Nevertheless, the results obtained using this methodology give an approximation to the reality that, in a future research, it is going to complete through a quantitative study that will validate the theoretical model.

Author Contributions: “Conceptualization, B.C.M.-A., P.E.L.-S. and C.S.-B.; methodology, B.C.M.-A., P.E.L.-S., and C.S.-B.; software, C.S.-B.; validation, B.C.M.-A., P.E.L.-S. and C.S.-B.; formal analysis, B.C.M.-A., P.E.L.-S. and C.S.-B.; investigation, B.C.M.-A., P.E.L.-S. and C.S.-B.; data curation, B.C.M.-A., P.E.L.-S. and C.S.-B.; writing-original draft preparation, B.C.M.-A.; writing-review and editing, B.C.M.-A., P.E.L.-S. and C.S.-B.; visualization, B.C.M.-A., P.E.L.-S. and C.S.-B.; supervision, B.C.M.-A.; project administration, B.C.M.-A.; funding acquisition, B.C.M.-A. All authors have read and agreed to the published version of the manuscript

Funding: This research was funded by the Junta de Extremadura (Spain) and European Regional Development Fund grant number IB18040 and GR18058 (SEJ022-Research Group INVE).

Conflicts of Interest: The authors declare no conflict of interest.

\section{References}

1. FoodDrinkEurope. Data and Trends. EU food \& Drink Industry, 2018. Available online: https://www.fooddr inkeurope.eu/uploads/publications_documents/FoodDrinkEurope_Data_and_Trends_2018_FINAL.pdf (accessed on 27 July 2020).

2. Ministerio de Agricultura, Alimentación y Medio Ambiente (MAGRAMA). Informe Anual de la Industria Alimentaria Española Período 2015-2016; Ministerio de Agricultura, Alimentación y Medio Ambiente (MAGRAMA): Madrid, Spain, 2016.

3. Corchuelo, B.; Mesías, F.J. Disposición a innovar y competitividad en la agroindustria extremeña. ITEA Inf. Tec. Econ. Agrar. 2017, 113, 176-191. [CrossRef]

4. Jiménez, J.D.; Sanz, V.R. Determinantes del éxito de la innovación. Rev. Empresa 2004, 7, $24-28$.

5. Kaufman, A.; Tödtling, F. How effective is innovation support for SMEs? An analysis of the region of Upper Austria. Technnovation 2002, 22, 147-159. [CrossRef]

6. Keizer, J.; Dijstra, L.; Halman, J.I.M. Explaining innovative efforts of pymes. An exploratory survey among pymes in the mechanical and electrical engineering sector in the Netherlands. Technovation 2002, 22, 1-13. [CrossRef] 
7. Zeng, S.X.; Xieb, X.M.; Tam, C.M. Relationship between cooperation network and innovation performance of SMEs. Technovation 2010, 30, 181-194. [CrossRef]

8. Buesa, M. I+D innovación tecnológica en las regiones españolas. Doc. Trab. IAIF 1998, 13, 1-26.

9. Buesa, M.; Martínez, M.; Heijs, H.; Baumert, T. Los sistemas regionales de innovación en España. Una tipología basada en indicadores económicos e institucionales. Econ. Ind. 2002, 347, 15-32.

10. Badiola, A.; Coto, P.P. Determinantes de la innovación tecnológica en las regiones españolas. In Proceedings of the International Conference on Regional Sciences y XXXVIII Reunión de Estudios Regionales-AECR, Bilbao, Spain, 22 November 2012.

11. Ruiz, F. I+D y territorio. Análisis y diagnóstico de la innovación empresarial en Andalucía. In Colección Premios de Investigación; Consejo Económico y Social de Andalucía: Seville, Spain, 2005.

12. EOI. Diagnóstico de Las Capacidades de Innovación de Las Pymes de Andalucía Y SU Incidencia en El Empleo, 2011. Available online: http://www.eoi.es/savia/documento/eoi-20192/diagnostico-de-las-capacida des-de-innovacion-de-las-pymes-de-andalucia-y-su (accessed on 18 May 2020).

13. López-Rodríguez, J.; Faiñas, A.; Manso, G. Sistemas de innovación regionales: El caso del País Vasco. Rev. Galega Econ. 2010, 19, 1-17.

14. Corchuelo, B.; Carvalho, A. Obstáculos a la Innovación y Políticas Públicas Orientadas al Fomento de la Innovación. In Anales de Economía Aplicada XXVII; Jiménez, J.M., Ed.; Delta Publicaciones: Madrid, Spain, 2013; pp. 231-251.

15. Corchuelo, B.; Mesías, F.J. Innovation in Extremadura: Opportunity for companies or obstacle for their development? In Handbook of Research and Entrepreneurial Success and its Impact on Regional Development; Carvalho, L.C., Ed.; IGI Global: Hershey, PA, USA, 2015; pp. 345-375. [CrossRef]

16. Cooke, P. Regional innovation systems: Origin of the species. Int. J. Techn. Learn. Inn. Dev. 2008, 1, $393-409$. [CrossRef]

17. Santos, D.; Simoes, M.J. Regional innovation systems in Portugal: A critical evaluation. Investig. Reg. 2014, $28,37-56$.

18. Niembro, A. Hacia una tipología de los sistemas regionales de innovación en Argentina. Investig. Reg. 2017, 38, 117-149.

19. Zukauskaite, E. Variety of Regional Innovation Systems and their institutional characteristics. In New Avenues for Regional Innovation Systems-Theoretical Advances, Empirical Cases and Polity Lessons; Isaken, A., Martin, R., Trippl, M., Eds.; Springer: New York, NY, USA, 2018.

20. Avermaete, T. Systems of innovation: The case of small food firms in the EU. In Proceedings of the DRUID PhD Winter Conference, Aalborg, Denmark, 17-19 January 2002; Available online: www.druid.dk/conferenc es/winter2002/gallery/avermaete.pdf (accessed on 18 May 2020).

21. Avermaete, T.; Viaene, J.; Morgan, E.J.; Crawford, N. Determinants of innovation in small food firms. Eur. J. Innov. Manag. 2003, 6, 8-17. [CrossRef]

22. Menrad, K. Innovations in the food industry in Germany. Res. Policy 2004, 33, 845-878. [CrossRef]

23. Avermaete, T.; Viaene, J.; Morgan, E.J.; Pitts, E.; Crawford, N.; Mahon, D. Determinants of product and process innovation in small food manufacturing firms. Trends Food Sci. Technol. 2004, 15, 474-483. [CrossRef]

24. Traill, W.B.; Meulenberg, M. Innovation in the food industry. Agribusiness 2002, 18, 1-21. [CrossRef]

25. Capitanio, F.; Coppola, A.; Pascucci, S. Product and process innovation in the Italian food industry. Agribusiness 2010, 26, 503-518. [CrossRef]

26. Baregheh, A.; Rowley, J.; Sambrook, S.; Davies, D. Innovation in food sector SMEs. J. Small Bus. Enterp. Dev. 2012, 19, 300-321. [CrossRef]

27. Batterink, M.H.; Wubben, E.; Klerkx, L.; Omta, O. Orchestrating innovation networks: The case of innovation brokers in the agri-food sector. Entrep. Reg. Dev. 2010, 22, 47-76. [CrossRef]

28. Kumar, A.; Singh, R.K.; Sachin, M. Exploring the relationship between ICT, SCM practices and organizational performance in agri-food supply chain. Benchmarking 2020, 27, 1003-1041. [CrossRef]

29. Kafetzopoulos, D.; Vouzas, F.; Bin Fahd, M.F.; Skalkos, D. Developing and validating an innovation drivers' measurement instrument in the agri-food sector. Br. Food J. 2020, 122, 1199-1214. [CrossRef]

30. Ghadge, A.; Kara, M.E.; Mogale, D.G.; Choudhary, S.; Dani, S. Sustainability implementation challenges in food supply chains: A case of UK artisan cheese producers. Prod. Plan. Control. 2020, 1-16. [CrossRef] 
31. Fearne, A.; García-Álvarez-Coque, J.M.; López-García, T.; García, S. Innovative firms and the urban/rural divide: The case of agro-food system. Mang. Decis. 2013, 51, 1293-1310. [CrossRef]

32. Alarcón, S.; Sánchez, M. External and internal R\&D, capital investment and business performance in the Spanish agri-food industry. Am. J. Agric. Econ. 2012, 64, 654-675. [CrossRef]

33. Alarcón, S.; Sánchez, M. Cómo innovan y qué resultados de innovación consiguen las empresas agrarias y alimentarias españolas. Cuad. Estud. Agroaliment. 2014, 6, 63-82.

34. Alarcón, S.; Sánchez, M. Relations between innovation activities and exports in food and agriculture firms. In Proceedings of the EAAE 2014 Congress Agri-Food and Rural Innovations for Healthier Societies, Ljubljana, Slovenia, 26-29 August 2014.

35. García-Álvarez-Coque, J.M.; Más-Verdú, F.; Sánchez, M. Determinants of agri-food firms' participation in public funded research and development. Agribusiness 2015, 31, 314-329. [CrossRef]

36. Alarcón, S.; González, L.; Sánchez, M. Strategies for the development of new products in the Spanish agri-food industry. In E-Innovation for Sustainable Development of Rural Resources During Global Economic Crisis; IGI Global: Hershey, PA, USA, 2014.

37. Arias, P.; Alarcón, S.; Botey, M. La caracterización a través del análisis factorial de las empresas agroalimentarias según sus obstáculos a la innovación. Econ. Ind. 2016, 400, 139-149.

38. Corchuelo, B.; Martín-Vegas, F. Characteristics of Extremaduran agri-food companies according to innovation strategies. Technol. Transf. Entrep. 2019, 6, 10-24. [CrossRef]

39. Corchuelo, B.; Ferreiro, F.J. Ari-food industry in Extremadura: Obstacles to innovation, willingness to innovate, and demanded public actions. Investig. Reg. 2019, 45, 191-199.

40. Leonard, D.; Straus, S. Putting your company's whole brain to use. Harv. Bus. Rev. 1997, 75, $110-121$. [CrossRef]

41. Shahzad, F.; Xiu, G.Y.; Shahbaz, M. Organizational culture and innovation performance in Pakistan's software industry. Technol. Soc. 2017, 51, 66-73. [CrossRef]

42. Dabic, M.; Laznjak, J.; Smallbone, D.; Svarc, J. Intellectual capital, organisational climate, innovation culture, and SME performance. J. Small Bus. Enterp. Dev. 2018, 26, 522-544. [CrossRef]

43. Padilha, C.K.; Gomes, G. Innovation culture and performance in innovation of products and processes: A study in companies of textile industry. RAI Rev. Adm. Inovação 2016, 13, 285-294. [CrossRef]

44. Curteanu, D.; Constantin, I. Organizational culture diagnosis-A new model. Manag. J. Fac. Bus. Adm. Univ. Buchar. 2010, 11, 14-21.

45. Pierce, J.L.; Delbecq, A.L. Organization structure, individual attitudes and innovation. Acad. Manag. Rev. 1977, 2, 27-37. [CrossRef]

46. Miles, R.E.; Snow, C.C.; Meyer, A.D.; Coleman, H.J. Organizational strategy, structure, and process. Acad. Manag. Rev. 1978, 3, 546-562. [CrossRef]

47. Martin-Rios, C.; Ciobanu, T. Hospitality innovation strategies: An analysis of success factors and challenges. Tour. Manag. Perspect. 2019, 70, 218-229. [CrossRef]

48. Wei, S.; Zhang, Z.; Ke, G.Y.; Chen, X. The more cooperation, the better? Optimizing enterprise cooperative strategy in collaborative innovation networks. Physica A 2019, 534, 1-12. [CrossRef]

49. Gallowaya, T.L.; Millerb, D.R.; Sahaymc, A.; Arthurs, J.D. Exploring the innovation strategies of youngfirms: Corporate venturecapital and venture capital impact on alliance innovation strategy. J. Bus. Res. 2017, 71, 55-65. [CrossRef]

50. Hittmár, S.; Varmus, M.; Lendel, V. Proposal of model for effective implementation of innovation strategy to business. Procedia Soc. Behav. Sci. 2014, 109, 1194-1198. [CrossRef]

51. Prajogo, D.I. The strategic fit between innovation strategies and business environment in delivering business performance. Int. J. Prod. Econ. 2014, 171, 241-249. [CrossRef]

52. Naqshbandi, M.M.; Jasimuddin, S.M. Knowledge-oriented leadership and open innovation: Role of knowledge management capability in France-based multinationals. Int. Bus. Rev. 2018, 27, 701-713. [CrossRef]

53. Cabello-Medina, C.; Carmona-Lavado, A.; Cuevas-Rodríguez, G. A contingency view of Alliance management capabilities for innovation in the biotech industry. BRQ Bus. Res. Q. 2019, in press. [CrossRef]

54. Al-Belushi, K.I.A.; Stead, S.M.; Burguess, J.G. Measurement of open innovation in the marine biotechnology sector in Oman. Mar. Policy 2018, 98, 164-173. [CrossRef] 
55. Silviana, B.G. Open innovation model: Enabling the market uptake of innovation. Procedia Manuf. 2018, 22, 893-899. [CrossRef]

56. Lopes, A.P.; Monteiro de Carvalo, M. Evolution of the open innovation paradigm: Towards a contingent conceptual model. Technol. Forecast. Soc. Chang. 2018, 132, 284-298. [CrossRef]

57. Mei, L.; Zhang, T.; Chen, J. Exploring the effects of inter-firm on SMEs' open innovation from an ecosistem perspective: An emprirical study of Chinese manufacturing SMEs. Technol. Forecast. Soc. Chang. 2019, 144, 118-128. [CrossRef]

58. Radziwon, A.; Bogers, M. Open innovation in SMEs: Exploring inter organizational relationships in an ecosystem. Technol. Forecast. Soc. Change. 2018, 146, 1-15. [CrossRef]

59. Lewin, A.Y.; Välikangas, L.; Chen, J. Enabling open innovation, lessons from Haier. Int. J. Innov. Stud. 2017, 1, 5-19. [CrossRef]

60. Van Lancker, J.; Wauters, E.; Van Huylenbroeck, G. Managing innovation in the bioeconomy: An open innovation perspective. Biomass Bioenergy 2016, 90, 60-69. [CrossRef]

61. Hernández-Vivanco, A.; Cruz-Cázares, C.; Bernardo, M. Openness and management system integration: Pursuing innovation benefits. J. Eng. Technol. Manag. 2018, 49, 76-90. [CrossRef]

62. Koster, M.; Vos, B.; Schroeder, R. Management innovation driving sustainable supply management: Process studies in exemplar MNEs. BRQ Bus. Res. Q. 2017, 20, 240-257. [CrossRef]

63. Roehrich, J.K.; Davies, A.; Frederiksen, L.; Sergeeeva, N. Management innovation in complex products and systems: The case of integrated project teams. Ind. Mark. Manag. 2019, 79, 84-93. [CrossRef]

64. Lendel, V.; Hitmár, S.; Siantová, E. Management of innovation processes in company. Procedia Econ. Financ. 2015, 23, 861-866. [CrossRef]

65. Hullova, D.; Simms, C.D.; Trott, P.; Laczko, P. Critical capabilities for effective management of complementary between product and process innovation: Cases from the food and drink industry. Res. Pol. 2019, 48, 339-354. [CrossRef]

66. García-Morales, V.J.; Jiménez-Barrionuevo, M.M.; Gutierrez-Gutierrez, L. Transformational leadership influence on organizational performance through organizational learning and innovation. J. Bus. Res. 2012, 65, 1040-1050. [CrossRef]

67. Wang, D.; Su, Z.; Guo, H. Top Management team conflict and exploratory innovation: The mediating impact of market orientation. Ind. Mark. Manag. 2019, 82, 87-95. [CrossRef]

68. Teece, D.J. Business models, business strategy and innovation. Long Range Plan. 2010, 43, 172-194. [CrossRef]

69. Alshanty, A.M.; Emeagwali, O.L. Market-sensing capability, knowledge creation and innovation: The moderating role of entrepreneurial-orientation. J. Innov. Knowl. 2019, 4, 171-178. [CrossRef]

70. Ho, K.L.P.; Nguyen, C.N.; Adhikari, R.; Miles, M.P.; Bonney, L. Exploring market orientation, innovation, and financial performance in agricultural value chains in emerging economies. J. Innov. Knowl. 2018, 3, 154-163. [CrossRef]

71. Ozkaya, E.; Droge, C.; Hult, T.M.; Calantone, R.; Ozkaya, R. Market orientation, knowledge competence, and innovation. Int. J. Res. Mark. 2015, 32, 309-318. [CrossRef]

72. Popa, S.; Soto-Acosta, P.; Martinez-Conesa, I. Antecedents, moderators, and outcomes of innovation climate and open innovation: An empirical study in SMEs. Technol. Forecast. Soc. Change. 2017, 118, 134-142. [CrossRef]

73. Fomujang, V.A.; Wu, C.; Tassang, A. The assesment of a creative climate within an organization. Int. J. Sci. Res. 2018, 8, 1-8.

74. Ruiz, J.I. Metodología de la Investigación Cualitativa, 4th ed.; Universidad Deusto: Bilbao, Spain, 2007.

75. Yin, R.K. Case Study Research: Design and Methods (Applied Social ResearchMethods); Sage: Newbury Park, CA, USA, 1989.

Publisher's Note: MDPI stays neutral with regard to jurisdictional claims in published maps and institutional affiliations. 